\title{
Perceived Poverty and Life Satisfaction in College Students with Impoverished Backgrounds: The Mediating Role of Self-Esteem
}

\author{
Bin Liu, Shuangle Fu \\ School of Social and Behavioral Sciences, Nanjing University, Nanjing, Jiangsu, People's Republic of China \\ Correspondence: Shuangle Fu, School of Social and Behavioral Sciences, Nanjing University, No. 163, Xianlin Road, Qixia District, Nanjing, 210023, \\ Jiangsu Province, People's Republic of China, Tel +86 I52 5I89 6029, Email hdsgfsIII0I@|26.com
}

Background: Perceived poverty is a common psychological feeling among college students with impoverished backgrounds. Perceived poverty can harm impoverished college students' interpersonal interactions, psychological health and life satisfaction. This study explored the effect of perceived poverty on the life satisfaction of impoverished college students and the mediating role of self-esteem.

Methods: In this cross-sectional study, 1044 impoverished college students from 22 universities completed an online questionnaire that included a measure of perceived poverty, self-esteem scale (SES) and satisfaction with life scale (SWLS). Mplus statistical software was used to test whether self-esteem mediates the relationship between perceived poverty and life satisfaction.

Results: Perceived poverty and life satisfaction were significantly negatively correlated, self-esteem was significantly positively correlated with life satisfaction, and perceived poverty was significantly negatively correlated with self-esteem. The structural equation model revealed that self-esteem partially mediated the relationship between perceived poverty and life satisfaction.

Conclusion: Financial aid programmes should safeguard and strengthen impoverished students' self-esteem while also taking steps to lessen their perceived poverty.

Keywords: college financial aid system, relative poverty, low-income families, mental health

\section{Introduction}

Over the past decades, China has gradually developed a government-led student financial aid policy that covers education from preschool to graduate programmes. The tagline of the Ministry of Education of the People's Republic of China is "never let a kid drop out of school because of family difficulties", which reflects its goal of making it possible for children from lowincome families to attend college and not to be prevented from finishing their education because of financial restrictions. Completing higher education is the best way for students with impoverished backgrounds to interrupt the intergenerational transmission of poverty. According to statistics, approximately $20 \%$ of students in Chinese universities apply for state aid. ${ }^{1}$ Students with impoverished backgrounds can receive subsidies to meet their basic needs from the government, school, society and student loans. ${ }^{2}$ Even with this support, impoverished students can feel the impact of the poverty gap and economic pressure. Poverty is associated with increasing social-emotional and negative health consequences. ${ }^{3}$ Furthermore, economic stress affects the extent to which adolescents feel in control of their lives. ${ }^{4}$ For impoverished students, perceived poverty is a common psychological feeling generated by the college environment and reinforced by daily communications and individual behaviour. It can negatively impact interpersonal communication, mental health and life satisfaction.

Research on perceived poverty has focused on groups of young people who are already employed. ${ }^{5}$ Although college students with impoverished backgrounds play a major role in preventing intergenerational poverty transmission, there is little knowledge of how these adults who are not yet working are affected by perceived poverty. Furthermore, studies have identified that even high-income people can feel poor and that simply addressing financial poverty does not alleviate 
the perception of poverty, ${ }^{6}$ nor does it enhance life satisfaction. ${ }^{7}$ China's current financial aid policy can provide financial assistance to every poor student entering university, but this aid may also give them the status of poor students in their new environment. Previous research on the impact of perceived poverty on life satisfaction has mostly ignored impoverished populations receiving financial assistance, specifically whether their perceived poverty impacts their selfesteem, and indirectly their life satisfaction. This information is necessary for developing supports for the physical and mental health of college students with impoverished backgrounds.

\section{Perceived Poverty and Life Satisfaction}

Studies of the direct consequences of material deprivation and subjective poverty for mental health ${ }^{8,9}$ have found a direct link between income and subjective well-being. ${ }^{10-12}$ Other studies have indicated that money has the highest association with well-being. ${ }^{13,14}$ Modernisation has a smaller influence on households in isolated mountain communities in Nepal. In general, research has found that people's perceptions of their own poverty and consumption are a major predictor of subjective well-being. ${ }^{15}$ Some people who are not objectively poverty-stricken may feel poor in comparison with others, ${ }^{16}$ even though they come from high-income societies. ${ }^{6}$ In contrast, objectively poor people may not feel economically disadvantaged. Accordingly, those who feel poor may be more dissatisfied with their lives than those who are truly poor. ${ }^{17}$ Good economic conditions do not necessarily lead to improved happiness; on the contrary, subjective comparisons and perceptions of economic conditions can affect individuals' life satisfaction. ${ }^{8}$ Maslow's hierarchy of needs begins with the most fundamental physical requirements and progresses to psychological wants. ${ }^{18}$ The desire for self-esteem and respect from others is greatest during adolescence. ${ }^{19}$ Thus, we cannot conceptualise poverty only in terms of material deprivation; exploring the effects of feelings of poverty provides a new perspective on the disadvantages faced by many impoverished students.

\section{Perceived Poverty, Self-Esteem and Life Satisfaction}

Life satisfaction is a component of the cognitive dimension of subjective well-being; it refers to a person's overall assessment of their life situation. ${ }^{20-22}$ Life satisfaction is immensely significant to people, not only as a measure of subjective well-being but also as a foundation for making judgements about the quality of their lives. ${ }^{23,24}$ It is a necessary component of both physical and mental health. ${ }^{25}$ It is a vital indicator of personal well-being and attitude towards life and an essential component of positive psychology. ${ }^{26}$ Multiple discrepancies theory suggests that the concept of satisfaction indicates that different people have different ideas of what they want and what resources are needed. ${ }^{27}$ According to quality of life theory, a high quality of life should include happiness, meaningfulness and fulfilment of one's needs. ${ }^{28,29}$ Dissatisfaction with one's life can have adverse physical and psychological consequences. ${ }^{30}$ In general, life satisfaction is a broad term that encompasses both subjective and objective factors. ${ }^{31}$ A variety of factors, including personality and other stable characteristics, influence overall subjective well-being.

One study found a significant correlation between material abundance and perceived life satisfaction; the correlation showed that perceived life satisfaction was proportional to the availability of material resources, which differed among nations and among schools within a nation. ${ }^{32}$ Studies have shown that adolescent life satisfaction is particularly influenced by environmental circumstances and life stresses. ${ }^{33}$ Other studies have shown a statistically significant and positive association between household financial contentment and life satisfaction. ${ }^{34}$ Changes in financial position over time have also been found to be a substantial predictor of life satisfaction. In addition, financial pressures influence young people's emotions, leaving them unsatisfied with their circumstances and blocking their progress. ${ }^{4,35}$ Doyal and Gough investigated perceived economic hardship by analysing the gap between individuals' perceived needs and their resources $^{36}$ and then classifying people as poor or non-poor based on the size of the reported gap and the level of stress. ${ }^{37}$ Some studies have found that people who perceive themselves as poor have lower life satisfaction than people who do not perceive themselves as poor. ${ }^{38,39}$

Self-esteem is directly tied to a person's appraisal of their worth. ${ }^{40}$ Both theoretically and empirically, ${ }^{41-44}$ selfesteem and life satisfaction are strongly associated, and people with high self-esteem are more likely to experience pleasant sensations and higher self-evaluations. ${ }^{45,46}$ Self-esteem is an important component of personality self-regulation, and high self-esteem can reduce the effects of stress and depression. ${ }^{47}$ Impoverished people frequently blame their 
financial conditions on ineptitude, cognitive biases, or personality. Their self-esteem suffers greatly when they cannot improve their financial situation. ${ }^{48}$ This implies that poverty causes or contributes to poor self-esteem issues, ${ }^{49}$ while wealth can help generate strong self-esteem. ${ }^{50}$ Others studies have suggested that the impoverished are more likely to blame external factors (eg, unfair laws, lack of social benefits) for their economic status, and thus maintain their selfesteem despite their low income. ${ }^{51}$

The "ability to live without shame" is a fundamental goal that should be integrated into concepts of poverty. ${ }^{52}$ Yaqub argued that it is important to include functional factors such as self-esteem in anti-poverty programmes. ${ }^{53}$ Alkire and Sarwar suggested that self-esteem is a valid factor in measures of poverty. ${ }^{54}$ Research has shown that perceived poverty affects life satisfaction both directly and indirectly through self-esteem. ${ }^{55,56}$ Cross-sectional studies have examined the impact of material poverty and family socioeconomic status but there have been few studies on perceived poverty, and self-esteem is rarely considered in either type of study. Therefore, this study used structural equation modelling (SEM) to examine the effects of self-esteem on the relationship between perceived poverty and life satisfaction. We made the following hypotheses.

H1: Perceived poverty has a significant negative impact on impoverished students' life satisfaction.

H2: Perceived poverty is negatively correlated with the self-esteem of impoverished students.

H3: Self-esteem has a significant positive impact on impoverished students' life satisfaction.

H4: Self-esteem mediates the effect of perceived poverty on the life satisfaction of impoverished students.

\section{Methods}

\section{Participants and Procedure}

The data used in this study were taken from the Tao Students Panel Survey (TSPS). The survey was conducted in March 2021 by a research team from Nanjing University, as part of a project funded by Jiangsu Tao Shing Pee Education Foundation. Each year, the foundation sponsors 50 impoverished rural college students in each grade at 22 institutions in Jiangsu province, China. They are chosen for the foundation's programme from the pool of students who meet the national financial aid requirements for students; the grants are made on the basis of three criteria: "from a rural area", "poor" and "has aspirations". First, they meet the national financial aid requirements for impoverished students; second, their Hukou (household registration) is in the rural area; finally, the individual must have certain expectations and plans for the future. Based on the three prerequisites listed above, the school's financial aid department publishes an application notification, the student submits an application form, the school checks the documents, and an interview is scheduled to selects the students who are more eligible for financial aid. Due to the COVID-19 pandemic, it was difficult to implement face-to-face surveys in 2021. In February 2021, the research team used the Questionnaire Star to design and complete an electronic questionnaire, which was then distributed to each college student who had received financial aid from the Jiangsu Tao Shing Pee Education Foundation as on 1 March 2021 via the email address provided by the students when they applied for financial aid. The respondents had to complete the questionnaire before 31 March 2021. The research team distributed 1100 questionnaires and received 1044 effective responses, giving a $94.9 \%$ recovery rate. There were 361 (34.58\%) male participants and 683 (65.42\%) female participants. All of the participants were between the ages of 17 and 25, with an average age of 19.62 years. In terms of family structure, 190 (18.20\%) were only children and $854(81.80 \%)$ were from non-only child families. There were $294(28.16 \%)$ people whose families were covered by the National Minimum Security Policy (Dibao). Annual family economic income ranged from 0 to 150,000 RMB, with a mean value of 31,700 RMB. The descriptive statistics of the research sample are displayed in Table 1.

\section{Ethical Statement}

The Ethics Committee of Nanjing University's School of Social and Behavioral Sciences authorised this study, which was carried out in strict conformity with the Declaration of Helsinki. The Ethics Committee discussed the participation of the very small number of participants under the age of 18 and came to the consensus that they were able to make decisions for themselves. As they were enrolled at university and were living independently, they were considered able to provide 
Table I Descriptive Characteristics of the Sample $(\mathrm{N}=1044)$

\begin{tabular}{|l|c|c|c|c|}
\hline Variables & M & S.D. & Min & Max \\
\hline Age & 19.62 & 0.89 & 17 & 25 \\
Gender & 0.35 & 0.48 & 0 & $\mathrm{I}$ \\
Family structure & 0.82 & 0.39 & 0 & $\mathrm{I}$ \\
National Minimum Livelihood Security & 0.72 & 0.45 & 0 & $\mathrm{I}$ \\
Family income & 3.17 & 2.05 & 0 & 15 \\
\hline
\end{tabular}

Abbreviations: M, mean; S.D., standard deviation.

informed consent on their own behalf and did not require informed parental consent. Written consent was obtained from each participant prior to the completion of the questionnaire. The participants were told the objective and substance of the study and were informed that the information they supplied would be kept absolutely confidential. The participants were given the option to refuse to complete the questionnaire or to stop answering it at any time if they had any reservations.

\section{Perceived Poverty}

To assess perceived poverty, we used a composite variable developed by the research team that included three single-item indicators. The first indicator was designed to assess the extent to which impoverished college students' families could afford their essential living expenses: "Is your family, in your opinion, financially capable of meeting its basic needs, such as clothes, food, housing, transportation and so on?" The options ranged from 1 (extremely satisfied) to 5 (extremely dissatisfied). The second and third indicators were used to calculate the level of perceived poverty by asking the impoverished college students to compare themselves with their neighbours, classmates and other persons with whom they often interact in daily life: "How does your family"s financial status compare to that of most of your neighbours?' and "How does your family"s financial status compare to that of most of your classmates?' The respondents were asked to score each item on a scale of 1 to 5, with 1 indicating that the neighbours/classmates had a much lower financial status and 5 indicating that they had a much higher financial status. For all three questions, higher scores indicated higher perceived poverty.

\section{Self-Esteem}

The Self-esteem Scale (SES) was used in this study to measure the self-esteem of impoverished college students. The scale, developed by Rosenberg, ${ }^{57}$ is used to measure adolescents' general feelings of self-worth and self-acceptance and consists of 10 questions, such as "I am positive about myself" and "I often think I am worthless". The respondents were asked to score each item on a scale of 1 to 5, with 1 representing strong disagreement and 5 representing strong agreement. The Chinese version of the Rosenberg Esteem Scale has been adapted for the Chinese context and is widely used in psychology. Liu and collaborators noted that the SES is highly reliable and valid. ${ }^{58}$ In this study, the Cronbach's alpha for the scale was 0.85 .

\section{Life Satisfaction}

This study adopted the most extensively used satisfaction with life scale (SWLS) to assess impoverished college students' overall perceptions and judgements of their living situations. ${ }^{23}$ This scale consists of five short questions. Respondents were asked to score each item on a scale of 1 to 7 , with 1 indicating that the statement is strongly inconsistent with their current life and 7 representing a statement that closely matches their lives. A higher score indicates greater life satisfaction. In the Chinese population, the SWLS has been shown to have extremely high reliability and validity. ${ }^{59}$ In this study, the Cronbach's alpha for the scale was 0.84 .

\section{Control Variables}

In our analysis, we also controlled for some personal characteristics, including age, gender, family structure, national minimum subsistence allowance and household income. Age was measured in years. Gender was a dummy variable $(0=$ male, 1 = female). Family structure was measured using dummy variables: a household with only one child (0) and 
a household with more than one child (1). The National Minimum Livelihood Security (Dibao) variable distinguished between households that received the support $($ receipt $=0$ ) and those that did not receive the support (non-receipt $=1$ ). Household income was a continuous variable measured in tens of thousands.

\section{Data Analysis}

Before starting the analysis, we cleaned the data using SPSS 22.0 and redistributed odd values using means. We performed a descriptive statistical analysis of the fundamental variables, calculating their means and standard deviations, and a Pearson correlation analysis to reveal the relationships between the three main variables. Then, we used Mplus 8.0 to conduct an SEM analysis to validate the hypothesised model and assess the instrument's psychometric qualities. As there were 10 questions in the SES, it was possible that a high number of latent variables could generate measurement errors. ${ }^{60}$ Therefore, we used the random assignment method to divide the self-esteem items into three parcels.

The fit of the model was examined before the model results were analysed. The following indicators were used to assess the fit. (a) Chi-square $\left(\chi^{2}\right)$ statistic, which is judged to be "preferable" if the value of $\chi^{2} / \mathrm{df}$ is smaller than 3 and "reasonable" if it is smaller than 5. (b) Comparative fit index (CFI) and Tucker-Lewis index (TLI); values greater than 0.90 are desirable for both indicators. ${ }^{61,62}$ (c) Root mean square error of approximation (RMSEA); a good match is indicated by values smaller than 0.06. (d) Standardised root mean square residual (SRMR); values smaller than 0.08 indicate a good fit. ${ }^{63}$ In this study, all five fit indices were used to analyse the model's fit.

The bias-corrected (BC) bootstrap method can directly provide standard error and confidence interval (CI) estimates for complicated distribution estimations (eg, percentiles, proportions, dominance ratios and correlation coefficients) with higher statistical power than other methods for conducting mediated effects analysis. ${ }^{64,65}$ In addition, bootstrapping is commonly used to test the utility of multiple mediating effects. ${ }^{66,67}$ Bootstrapping methods also reduce costs by eliminating the need for multiple trials to collect data. This study used the BC bootstrapping method with 5000 replication samples to determine whether self-esteem mediated the relationship between perceived poverty and life satisfaction. The CI was $95 \%$, which meant that the model could detect a substantial mediating impact if zero was not included within the $95 \%$ CI. The outcomes of the mediation effect were measured using standardised indicators.

\section{Results}

This section presents the findings of the correlation analysis, measurement model, structural model and mediation effects. The following section presents the findings of the correlation analysis of the dependent and independent variables.

\section{Descriptive Analysis}

The results of the descriptive and correlation analysis are shown in Table 2. Perceived poverty was negatively correlated with self-esteem $(r=-0.153, p<0.001)$ and life satisfaction $(r=-0.257, p<0.001)$, and self-esteem was positively correlated with life satisfaction $(r=0.425, \mathrm{p}<0.001)$. The above findings supported our hypothesis of a mediating effect.

\section{The Measurement Model}

The measurement model considered 3 latent factors and 11 observed variables. The factor loading of each measurement index was significant in the measurement model. Specifically, $\chi^{2}=119.531, d f=41, \mathrm{p}<0.001, \mathrm{CMIN} / \mathrm{DF}=2.915, \mathrm{CFI}=$

Table 2 Means, Standard Deviations and Correlations Between the Variables

\begin{tabular}{|l|c|c|c|c|c|}
\hline & M & S.D. & Perceived Poverty & Self-Esteem & Life Satisfaction \\
\hline Perceived poverty & 3.870 & 0.448 & $\mathrm{I}$ & & \\
Self-esteem & 3.884 & 0.543 & $-0.153^{* * *}$ & $\mathrm{I}$ & \\
Life satisfaction & 4.323 & 1.070 & $-0.257^{* * *}$ & $0.425^{* * *}$ & $\mathrm{I}$ \\
\hline
\end{tabular}

Notes: $\mathrm{N}=1044$. $* * * p<0.001$.

Abbreviations: M, mean; S.D., standard deviation. 
$0.983, \mathrm{TLI}=0.977, \mathrm{RMSEA}=0.043, \mathrm{SRMR}=0.031$. The above findings demonstrated that each latent factor accurately reflected its corresponding indicator.

\section{The Structural Model}

The structural model examined the impact of perceived poverty on life satisfaction and the mediating effect of selfesteem (Figure 1).

The structural model's fit indicators were $\chi 2=296.723, d f=91, \mathrm{p}<0.001, \mathrm{CMIN} / D F=3.261, \mathrm{CFI}=0.956$, TLI= 0.947 , RMSEA $=0.047, \mathrm{SRMR}=0.048$, indicating that the model had a good fit. There was a significant negative relationship between perceived poverty and self-esteem $(\beta=-0.19, \mathrm{p}<0.001)$. In other words, higher perceived poverty was associated with lower self-esteem. Moreover, consistent with prior findings, self-esteem had a statistically significant positive impact on life satisfaction $(\beta=0.497, \mathrm{p}<0.001)$. The direct route coefficient from perceived poverty to life satisfaction had a statistically significant negative influence $(\beta=-0.214, p<0.001)$. These results indicated that self-esteem mediates the relationship between perceived poverty and life satisfaction.

\section{The Mediating Analysis}

As shown in Table 3, the overall effect of perceived poverty on life satisfaction was significant $(\beta=-0.308,95 \% \mathrm{CI}=$ $[-0.385,-0.229])$. Its direct effect was significant $(\beta=-0.214,95 \% \mathrm{CI}=[-0.288,-0.138])$, accounting for $69.48 \%$ of the total effect. The mediation model showed that the indirect effect of perceived poverty on life satisfaction, mediated by self-esteem, was also significant $(\beta=0.094,95 \% \mathrm{CI}=[-0.138,-0.054])$, accounting for $30.52 \%$ of the overall effect. The results confirmed that when perceived poverty increases, self-esteem and life satisfaction decrease.

\section{Discussion}

This study used SEM to analyse the effect of self-esteem on the relationship between perceived poverty and life satisfaction among impoverished college students. The findings indicated that perceived poverty had a significant negative influence on life satisfaction regardless of whether self-esteem was considered, but that self-esteem had a partly mediating function. As hypothesised, we found that self-esteem had a significant indirect effect on the relationship between perceived poverty and life satisfaction, reducing the influence of the former on the latter. Future studies should pay greater attention to the function of self-esteem in the relationship between perceived poverty and life satisfaction. Practical interventions for enhancing the poor's life satisfaction should recognise the role of a wider range of factors. Individual mindsets can be adjusted to reduce perceptions of poverty and boost self-esteem.

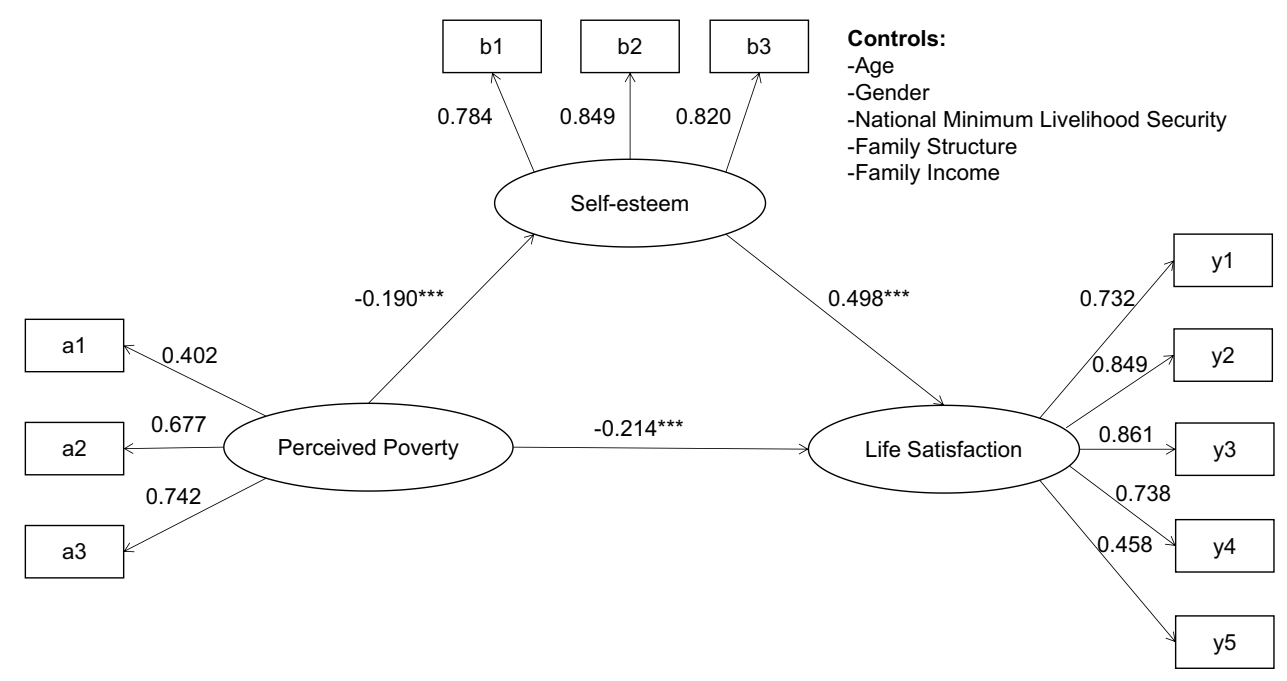

Figure I Model of interrelations between perceived poverty, self-esteem and life satisfaction. Note: $* * * p<0.001$. 
Table 3 Bootstrap Analysis of the Magnitude and Statistical Significance of Indirect Effects

\begin{tabular}{|l|c|c|c|c|}
\hline & Model Pathways & $\boldsymbol{\beta}$ Standardised Indirect Effect & BootSE & $\mathbf{9 5 \%}$ CI \\
\hline $\mathrm{I}$ & Direct Effect & -0.214 & 0.038 & {$[-0.288,-0.138]$} \\
2 & $\mathrm{PP} \rightarrow$ SE $\rightarrow$ LS & -0.094 & 0.022 & {$[-0.138,-0.054]$} \\
3 & Total Effect & -0.308 & 0.040 & {$[-0.385,-0.229]$} \\
\hline
\end{tabular}

Notes: $N=1044$. These values are based on unstandardised path coefficients.

Abbreviations: PP, perceived poverty; SE, self-esteem; LS, life satisfaction; Cl, confidence interval.

These findings were consistent with prior research. Academics have noted that comparing one's financial resources with others has a detrimental influence on psychological well-being even for people who are no longer living in extreme poverty. ${ }^{68,69}$ The college students in this study were labelled poor because their families could not pay their college fees. These college students lack some of the material things owned by non-poor college students and have notably different lifestyles and consumption habits. The experience of relative poverty induced by comparing themselves with their peers may have long-term effects on impoverished college students, such as feelings of inferiority or other unpleasant emotions and a decrease in their life satisfaction and subjective well-being.

This study found that impoverished college students with high self-esteem had higher life satisfaction, which is consistent with previous studies. Xin found that impoverished students with high self-esteem were more eager to escape poverty via their efforts, and this compensated for the lack of educational resources and poor familial background. ${ }^{70}$ Ding and Wang discovered that impoverished college students with strong self-esteem believed poverty was simply a transitory condition. They had high expectations of themselves in their studies and daily lives, and they did not view poverty as a hardship. In other words, impoverished students with high self-esteem are more likely to exhibit positive attributes. ${ }^{71}$ However, impoverished college students with low self-esteem are more likely to have negative feelings. They are more sensitive to negative evaluations and overlook favourable evaluations. They are more likely to be labelled gloomy and pessimistic, may avoid obstacles, and are hesitant to participate in social activities. As Qiu and Tang found, impoverished students with low self-esteem are more likely to adopt an escapist attitude when faced with difficulties; they do not participate in competitive activities because they have doubts about their ability. ${ }^{72}$

This study has confirmed that perceived poverty is negatively correlated with self-esteem, and will thus make impoverished students more prone to negative emotions such as an inferiority complex and bias in self-cognition. Schat and Desmarais found that aspects of personality were associated with a person's attitude towards money; in particular, pessimism was associated with a negative affect towards money. ${ }^{73}$ Impoverished college students who enter university with low self-esteem will be more influenced by the new environment and more concerned about the outside world's assessment of them, and will thus have a greater feeling of perceived poverty than others. Money and self-esteem both impact life satisfaction, and they may be substitutable. ${ }^{74,75}$ However, a strong sense of perceived poverty makes it difficult to feel positive about one's life and to build self-esteem.

The financial problems of impoverished college students are easily transformed into psychological problems, making them "double stranded" (economic and psychological) problems. ${ }^{58}$ This study showed that self-esteem can mitigate the harmful influence of perceived poverty on the life satisfaction of impoverished college students. Therefore, we should protect the self-esteem of impoverished college students by protecting their privacy when they are applying for financial aid. Second, psychological counselling should be available to impoverished college students, to help them to face life with an optimistic attitude and to use positive actions to boost self-esteem.

The perceived poverty and life satisfaction of impoverished college students and their interactions are influenced by various individual, social and economic factors; thus, self-esteem may be merely one of several contributing elements. This study found that perceived poverty had a significant negative effect on life satisfaction even after controlling for self-esteem. Although self-esteem's mediating role was supported by its indirect impact of $30.52 \%$, these results also indicated that there are other mediators. The relationship between poverty perception and life satisfaction among impoverished college students is multifaceted, and this study focused on the impact of only one mediating factor: selfesteem. 


\section{Limitations and Future Research Directions}

This study used a sample of 1044 impoverished Chinese college students to examine the mediating role of self-esteem in the relationship between perceived poverty and life satisfaction. The findings have important implications for improving the selfesteem and life satisfaction of impoverished college students. However, the study has some limitations and deficiencies. First, perceived poverty was measured using three simple indicators. Future research could add variables such as the standard of consumption and school life to obtain a fuller picture of perceived poverty. Second, the data used in the study were crosssectional. Thus, causal relationships between perceived poverty and life satisfaction could not be determined. Longitudinal data might be used to examine the directional influences of perceived poverty, self-esteem and life satisfaction. In addition, the participants were first-year college students. We intend to do a follow-up survey in their senior year. We will ask the same students to complete the same questionnaire so that we can examine how poverty perception, self-esteem and life satisfaction change over time. This will allow us to gain a more comprehensive and detailed understanding of the relationships between perceived poverty, self-esteem and life satisfaction. Third, the data were collected using an online survey. As responders are not supervised in this method, some of the participants may fill out the questionnaire casually or superficially and may have concealed information. Future studies should use methods to reduce these potential problems.

Furthermore, the findings showed that self-esteem is probably not the only mediating factors. Others, such as social support, may mediate the same relationship. The impact of these additional mediating factors should be examined in future investigations. Finally, non-impoverished college students were not included. Perceived poverty is a person's subjective feeling and it may or may not be connected to material deprivation. A materially impoverished person, for example, may not consider himself or herself poor, while a person whose life is not materially deprived may think himself or himself poor. Future research might include non-poor college students and compare the relationship between perceived poverty and life satisfaction in the two categories of college students. This study found that self-esteem mitigates the detrimental influence of perceived poverty on life satisfaction.

\section{Conclusion}

This study was the first to investigate the role of self-esteem as a mediator in the relationship between perceived poverty and life satisfaction in a sample of impoverished college students in China. First, the study found a significant direct link between perceived poverty and life satisfaction. Second, perceived poverty had a significant negative effect on self-esteem. Third, self-esteem had a mediating effect on the relationship between perceived poverty and life satisfaction. Finally, self-esteem is probably one of several mediating factors. Self-esteem significantly affected the impact of perceived poverty on life satisfaction. A high degree of self-esteem mitigated the detrimental influence of perceived poverty on life satisfaction. These findings have substantial implications for financial aid policy. Specifically, when providing financial aid to poor college students, we should also aim to develop a long-term system for supporting them and consolidating financial aid outcomes. In addition to ensuring the basic needs of poor college students, we should assist them in overcoming mental poverty and improving their self-esteem and psychological health, and promote social integration. Ensuring the comprehensive development of rural poor college students will consolidate and expand the outcomes of financial aid for college students. College instructors could help impoverished college students enhance their life satisfaction by improving their selfesteem. We anticipate that our findings will help to develop programmes that improve the life satisfaction of impoverished college students and stimulate further research into the connection between perceived poverty and life satisfaction.

\section{Acknowledgments}

We thank the Jiangsu Tao Shing Pee Education Foundation for allowing this project to collect data from impoverished college students.

\section{Author Contributions}

All authors made substantial contributions to conception and design, acquisition of data, or analysis and interpretation of data; took part in drafting the article or revising it critically for important intellectual content; agreed to submit to the current journal; gave final approval of the version to be published; and agree to be accountable for all aspects of the work. 


\section{Disclosure}

The authors declare no conflicts of interest in this study work.

\section{References}

1. Ministry of Education of the People's Republic of China. China student fi-nancial aid development report; 2021. Available from: http://www.xszz. cee.edu.cn/index.php/shows/70/7264.html. Accessed January 10, 2022.

2. Ministry of Education of the People's Republic of China. Opinions of the state co-uncil on establishing a sound financial assistance system for students from econ-omically disadvantaged families in general undergraduate universities, higher voc-ational schools and secondary vocational schools; 2007. Available from: http://www.moe.gov.cn/jyb_xxgk/moe_1777/moe_1778/tnull_27695.html. Accessed January 10, 2022.

3. Jorgensen DD. Concurrent enrollment programs and acquired social capital for students from impoverished backgrounds: an examination of high school and college outcomes. Electronic Theses and Dissertations; 2013. Available from: https://digitalcommons.du.edu/etd/325. Accessed September 12, 2021.

4. Conger RD, Ge XJ, Elder GH, Lorenz FO, Simons RL. Economic stress, coercive family process, and developmental problems of adolescents. Child Dev. 1994;65:541-561. doi:10.2307/1131401

5. Achdut N, Refaeli T. An ethnocultural perspective on loneliness in young adulthood: a population-based study in Israel. Sociol Health Ill. 2021;43:1154-1174. doi:10.1111/1467-9566.13277

6. Peng C, Yip PS, Law YW. What factors beyond economic poverty lead people in high-income societies to feel poor? Evidence from Hong Kong. Soc Indic Res. 2020;152:991-1027. doi:10.1007/s11205-020-02419-3

7. Yuan H. Structural social capital, household income and life satisfaction: the evidence from Beijing, Shanghai and Guangdong-Province, China. J Happiness Stud. 2016;17:569-586. doi:10.1007/s10902-015-9622-z

8. Achdut N, Refaeli T, Schwartz Tayri TM. Subjective poverty, material deprivation indices and psychological distress among young adults: the mediating role of social capital and usage of online social networks. Soc Indic Res. 2021;158:863-887. doi:10.1007/s11205-021-02729-0

9. Chung RY-N, Chung G-K-K, Gordon D, et al. Deprivation is associated with worse physical and mental health beyond income poverty: a population-based household survey among Chinese adults. Qual Life Res. 2018;27:2127-2135. doi:10.1007/s11136-018-1863-y

10. Argyle M. The Psychology of Happiness. London: Routledge; 2001.

11. Cramm JM, Moller V, Nieboer AP. Improving subjective well-being of the poor i-n the eastern cape. J Health Psychol. 2010;15:1012-1019. doi:10.1177/1359105310367833

12. Banerjee B, Kundu A. Subjective well-being of the informal workers: an empirical study from Hooghly district of West Bengal, India. Int J Happiness Dev. 2020;6:1-25. doi:10.1504/IJHD.2020.108753

13. Biswas-Diener R, Diener E. Making the best of a bad situation: satisfaction in the slums of Calcutta. Soc Indic Res. 2001;55:329-352. doi:10.1023/ A:1010905029386

14. Diener E, Lucas RE. Personality and subjective well-being. In: Schwarz N, Strack F, editors. The Foundations of Hedonic Psychology. New York: Russell Sage Foundation; 2000:213-229.

15. Fafchamps M, Shilpi F. Isolation and subjective welfare: evidence from South Asia. Econ Dev Cult Change. 2009;57:641-683. doi:10.1086/598761

16. Peng C. What makes people feel poor when they are economically non-poor? Investigating the role of intergenerational mobility and comparison with friends. Res Soc Strat Mobil. 2021;75:100645. doi:10.1016/j.rssm.2021.100645

17. Mahmood T, Yu X, Klasen S. Do the poor really feel poor? Comparing objective poverty with subjective poverty in Pakistan. Soc Indic Res. 2018;142:543-580. doi:10.1007/s11205-018-1921-4

18. Maslow AH. Motivation and Personality. New York, NY: Harper \& Row Publishers; 1954

19. Goebel BL, Brown DR. Age differences in motivation related to maslow's need hierarchy. Dev Psychol. 1981;17:809-815. doi:10.1037/00121649.17.6.809

20. Diener E, Suh E, Oishi S. Recent findings on subjective well being. India J Clin Psychol. 1997;24:25-41.

21. Peterson C, Park N, Seligman MEP. Orientations to happiness and life Satisfaction: the full life versus the Empty life. J Happiness Stud. 2005;6:25-41. doi:10.1007/s10902-004-1278-z

22. Singh K, Jha SD. Positive and negative affect, and grit as predictors of happiness and life satisfaction. J Indian Inst Sci. 2008;34:40-45.

23. Diener E, Emmons RA, Larsen RJ, Griffin S. The satisfaction with life scale. J Pers Assess. 1985;49:71-75. doi:10.1207/s15327752jpa4901_13

24. Lewis AD. Facilitating student engagement: the importance of life satisfactio-n. D-octoral dissertation; 2010. Available from: https://scholarcom mons.sc.edu/etd/210. Accessed February 9, 2022.

25. Frisch MB. Improving mental and physical health care through Quality of Life Therapy and assessment. In: Diener E, Rahtz DR, editors. Advances in Quality of Life Theory and Research. London: Kluwer Academic Press; 2000:207-241.

26. Gilman R, Huebner S. A review of life satisfaction research with children and adolescents. School Psychol Quart. 2003;18:192-205. doi:10.1521/ scpq.18.2.192.21858

27. Michalos AC. Multiple discrepancies theory (MDT). Soc Indic Res. 1985;16(4):347-413. doi:10.1007/BF00333288

28. Frisch MB. Quality of life therapy and assessment in health care. Clin Psychol (New York). 1998;5:19-40. doi:10.1111/j.1468-2850.1998.tb00132.x

29. Ventegodt S, Merrick J, Andersen NJ. The IQOL theory: an integrative theory of the global quality of life concept. Sci World J. 2003;3:1030-1040. doi:10.1100/tsw.2003.82

30. Gigantesco A, Fagnani C, Toccaceli V, et al. The relationship between satisfaction with life and depression symptoms by gender. Front Psychiatry 2019;10:419. doi:10.3389/fpsyt.2019.00419

31. Loewe N, Bagherzadeh M, Araya-Castillo L, Thieme C, Batista-Foguet JM. Life domain satisfactions as predictors of overall life satisfaction among workers: evidence from Chile. Soc Indic Res. 2014;118:71-86. doi:10.1007/s11205-013-0408-6

32. Main G, Montserrat C, Andresen S, Bradshaw J, Lee BJ. Inequality, material well-being, and subjective well-being: exploring associations for children across 15 diverse countries. Child Youth Serv Rev. 2017;97:3-13. doi:10.1016/j.childyouth.2017.06.033

33. McKnight CG, Huebner ES, Suldo S. Relationship among stressful life events, temperament, problem behaviour, and global life satisfaction in adolescents. Psychol Sch. 2002;39:677-687. doi:10.1002/pits.10062 
34. Boo MC, Yen SH, Lim HE. A note on happiness and life satisfaction in Malay-sia. Malaysian J Econ Stud. 2016;53:261-277.

35. Forkel I, Silbereisen RK. Family economic hardship and depressed mood among young adolescents from former East and West Germany. Am Behav Scient. 2001;44:1955-1971. doi:10.1177/00027640121958131

36. Doyal L, Gough I. A Theory of Human Need. Basingstoke: Macmillan; 1991.

37. Gasper D. Conceptualizing human needs and well-being. In: Gough I, McGregor JA, editors. Researching Well-Being in Developing Countries: From Theory to Research. Cambridge: Cambridge University Press; 2007:47-70.

38. Meyer DF, Dunga SH. The determinants of life satisfaction in a low-income, poor community in South Africa. Mediterr J Soc Sci. $2014 ; 5: 163$. doi:10.5901/mjss.2014.v5n13p163

39. Graafland J, Lous B. Income inequality, life satisfaction inequality and trust: a cross country panel analysis. J Happiness Stud. $2019 ; 20: 1717-1737$. doi:10.1007/s10902-018-0021-0

40. Orth U, Robins RW. The development of self-esteem. Curr Sci. 2014;23:381-387. doi:10.1177/0963721414547414

41. Mack JE. Self-esteem and its development: an overview. In: Mack JE, Ablon SL, editors. The Development and Sustenance of Self-Esteem in Childhood. New York: International Universities Press; 1983:1-42.

42. Hermans HJM. Unhappy self-esteem: a meaningful exception to the rule. J Psychol. 1992;126:555-570. doi:10.1080/00223980.1992.10543388

43. Sedikides C, Rudich EA, Gregg AP, Kumashiro M, Rusbult C. Are normal narcissists psychologically healthy: self-esteem matters. J Pers Soc Psychol. 2004;87:400-416. doi:10.1037/0022-3514.87.3.400

44. Kong F, Zhao J, You X. Emotional intelligence and life satisfaction in Chinese university students: the mediating role of self-esteem and social support. Pers Individ. 2012;53:1039-1043. doi:10.1016/j.paid.2012.07.032

45. Kwan VS, Bond MH, Singelis TM. Pancultural explanations for life satisfaction: adding relationship harmony to self-esteem. J Pers Soc Psychol. 1997;73:1038-1051. doi:10.1037/0022-3514.73.5.1038

46. Huo Y, Kong F. Moderating effects of gender and loneliness on the relationship between self-esteem and life satisfaction in Chinese University Students. Soc Indic Res. 2014;118:305-314. doi:10.1007/s11205-013-0404-x

47. Baumeister RF, Campbell JD, Krueger JI, Vohs KD. Does high self-esteem cause better performance, interpersonal success, happiness, or healthier lifestyles. Psychol Sci. 2003;4:1-44.

48. Dzuka J, Dalbert C. Mental health and personality of Slovak unemployed adolescents: the impact of belief in a just world. J Appl Soc Psychol. 2010;32:732-757. doi:10.1111/j.1559-1816.2002.tb00240.x

49. Batty E, Flint J. Self-esteem, comparative poverty and neighbourhoods. JRF Research Paper No. 7. Sheffield: Sheffield Hallam University, Centre for Regional, Economic and Social Research; 2010.

50. Russell AR, Nyame-Mensah A, de Wit A, et al. Volunteering and wellbeing among ageing adults: a longitudinal analysis. Voluntas. 2019;30:115-128. doi:10.1007/s11266-018-0041-8

51. Palomar J, Lanzagorta N, Hernández J. Poverty, psychological resources and subjective well-being. Soc Indic Res. 2005;73:375-408. doi:10.1007/ s11205-004-1072-7

52. Sen A. Poverty and Famines: An Essay on Entitlement and Deprivation. Oxford: Clarendon Press; 1981.

53. Yaqub S. Poor children grow into poor adults: "Harmful Mechanisms or Over-Deterministic Theory". J Int Dev. 2002;14:1081-1093. doi:10.1002/ jid.951

54. Alkire S, Sarwar M. Multidimensional measures of poverty \& well-being. Report Working Paper of Department of International Development Oxford; 2009. Available from: http:/www.ophi.org.uk/wp-content/uploads/OPHI-RP-6a.pdf. Accessed June $25,2021$.

55. Shek DTL. Economic disadvantage, perceived family life quality, and emotional well-being in Chinese adolescents: a longitudinal study. Soc Indic Res. 2008;85:169-189. doi:10.1007/s11205-007-9087-5

56. Bannink R, Pearce A, Hope S. Family income and young adolescents' perceived social position: associations with self-esteem and life satisfaction in the UK Millennium Cohort Study. Arch Dis Childhood. 2016;101(10):917-921. doi:10.1136/archdischild-2015-309651

57. Rosenberg M. Rosenberg self-esteem scale (RSE). Acceptance Commitment Therapy. 1965;61:52.

58. Liu XY, Xie T, Li W, et al. The relationship between perceived discrimination and wellbeing in impoverished college students: a moderated mediation model of self-esteem and belief in a just world. Curr Psychol. 2021. doi:10.1007/s12144-021-01981-4

59. Kong F, You X. Loneliness and self-esteem as mediators between social support and life satisfaction in late adolescence. Soc Indic Res. 2013;110:271-279. doi:10.1007/s11205-011-9930-6

60. Little TD, Cunningham WA, Shahar G, Widaman KF. To parcel or not to parcel: exploring the question, weighing the merits. Struct Equ Modeling. 2002;9:151-173. doi:10.1207/S15328007SEM0902 1

61. Bentler PM. Comparative fit indexes in structural models. Psychol Bull. 1990;107:238-246. doi:10.1037/0033-2909.107.2.238

62. Marsh HW, Hau K-T, Wen Z. In search of golden rules: comment on hypothesis-testing approaches to setting cutoff values for fit indexes and dangers in overgeneralizing Hu and Bentler's (1999) findings. Struct Equ Modeling. 2004;11:320-341. doi:10.1207/s15328007sem1103_2

63. Hu LT, Bentler PM. Cutoff criteria for fit indexes in covariance structure analysis: conventional criteria versus new alternatives. Struct Equ Modeling. 1999;6:1-55. doi:10.1080/10705519909540118

64. Fritz MS, MacKinnon DP. Required sample size to detect the mediated effect. Psychol Sci. 2007;18:233-239. doi:10.1111/j.1467-9280.2007.01882.x

65. Wen Z, Ye B. Analyses of mediating effects: the development of methods and models. Sci Adv. 2014;22:731-745.

66. Cheung MWL. Comparison of approaches to constructing confidence intervals for mediating effects using structural equation models. Struct Equ Modeling. 2007;14:227-246. doi:10.1080/10705510709336745

67. Lau RS, Cheung GW. Estimating and comparing specific mediation effects in complex latent variable models. Organ Res Methods. 2012;15:3-16. doi: $10.1177 / 1094428110391673$

68. Festinger L. A theory of social comparison processes. Hum Relat. 1954;7:117-140. doi:10.1177/001872675400700202

69. Brehm J, Festinger L. Pressures toward uniformity of performance in groups. Hum Relat. 1957;10:85-91. doi:10.1177/001872675701000106

70. Xin Y. A comparative study on self-esteem, social support and coping styles of poor college students. Heilongjiang Res Higher Edu. 2005;4:156-157.

71. Ding F, Wang Y. "Economic Poverty" or "Psychological Poverty": a new solution to happiness paradox. Youth Stud. 2011;72-80:96.

72. Qiu X, Tang J. A comparative study on the mental health status of poor college students. Seeker. 2011;175-176. doi:10.16059/j.cnki.cn43-1008/ c.2011.02.049 
73. Schat ACH, Desmarais S. Personality-based correlates of the multiple meanings of money. Unpublished research report. Guelph, Ontario, Canada: University of Guelph; 2003.

74. Zhang L. An exchange theory of money and self-esteem in decision making. Rev Gen Psychol. 2009;13:66-76. doi:10.1037/a0014225

75. Juneman MEA, Rahardjo W. Symbolic meaning of money, self-esteem, and identification with pancasila values. Int Congress Interdis Business Soc Sci. 2012;65:106-115. doi:10.1016/j.sbspro.2012.11.099

\section{Publish your work in this journal}

Psychology Research and Behavior Management is an international, peer-reviewed, open access journal focusing on the science of psychology and its application in behavior management to develop improved outcomes in the clinical, educational, sports and business arenas. Specific topics covered in the journal include: Neuroscience, memory and decision making; Behavior modification and management; Clinical applications; Business and sports performance management; Social and developmental studies; Animal studies. The manuscript management system is completely online and includes a very quick and fair peer-review system, which is all easy to use. Visit http://www.dovepress.com/testimonials.php to read real quotes from published authors.

Submit your manuscript here: https://www.dovepress.com/psychology-research-and-behavior-management-journal 